\title{
Human Papilloma Virus Vaccination Coverage among Soldiers in a Military Treatment Facility, 2007-2010
}

Justin D. LaRocque ${ }^{1}$ and Cristóbal S. Berry-Cabán ${ }^{2 *}$

${ }^{1}$ Womack Army Medical Center, Department of Pharmacy, Fort Bragg, North Carolina, USA

${ }^{2}$ Womack Army Medical Center, Department of Research, Fort Bragg, North Carolina, USA

\begin{abstract}
Background: Human Papillomavirus (HPV) is the most common sexually transmitted infection (STI) among soldiers in the US Army. This study examines compliance patterns of female soldiers who receive the HPV prevention vaccine Gardasil in a Military Treatment Facility.

Methods: Medical records of all female Soldiers aged 18 to 26 registered at Womack Army Medical Center ( $n$ $=3,186$ ) were examined retrospectively. Patients identified with a Current Procedural Terminology (CPT) 90649 Human Papillomavirus (HPV) vaccine code encounter were included. Data were collected for all patients between November 1, 2006 and December 15, 2009.

Results: Approximately 15\% received Gardasil; of these only 37\% completed the required 3-dose series.

Conclusions: A number of recommendations to increase initiation of the vaccine series are suggested. Steps should also be taken to educate providers in using required annual physicals to start a discussion of the vaccine and to administer the first dose. To increase the visibility of the vaccine, this education could be completed at educational lectures, at residency lectures or at staff meetings within clinic areas. This study is intended to remind providers to initiate the HPV vaccine series and the importance of completing the entire series in all eligible females.
\end{abstract}

\section{Introduction}

Human Papillomavirus (HPV) is the most common sexually transmitted infection (STI) among soldiers in the US Army [1,2]. In the US Military Health System, STI-related encounters are frequent and reflect the evaluation and treatment of symptomatic disease, screening to detect asymptomatic infections, and follow-up examinations. For several reasons, knowledge regarding the incidence and natures of STIs among US military members has significant current interest [1,3-6]. HPV infects the skin and mucous membranes of humans [7]. There are approximately $130 \mathrm{HPV}$ types that have been identified. Some HPV types can cause warts (verruca) or cancer, while others have no symptoms at all. Most sexually active persons will probably acquire a genital HPV infection at some point during their lives. About 30 to 40 HPV types are typically transmitted through sexual contact and infect the anogenital region. Some sexually transmitted HPV types may cause genital warts, while others do not cause any noticeable signs of infection. Persistent infection with "high-risk"HPV types- different from the ones that cause warts- may progress to precancerous lesions and invasive cancer. HPV infection is a cause of nearly all cases of cervical cancer [7]. Scientific data also links HPV infection to cervical cancer [8]. Women who fail to have regular cervical cancer screenings substantially increase their risk of developing cancer. An estimated $11 \%$ of US women do not have regular cervical cancer screenings. The American Cancer Society estimated that in 2008, about 11,070 women were diagnosed with invasive cervical cancer and about 3,870 US women will die from this disease [9].

Between 2004 and 2009, more service members were diagnosed with HPV than any other STI; the overall incidence rate of HPV was $2,305.9$ per 100,000 . Overall incidence rates of Chlamydia, herpes simplex virus (HSV), and gonorrhea were 926.2, 879.1, and 190.2 per 100,000 respectively; the rate of syphilis was much lower than the rates of the other STIs [2].

In general, STI rates were higher among female military members who are in their 20s, black, in the Army, and from the Southern region of the US. Between 2004 and 2009, an average of 27,745 service members per year had at least one HPV-related medical encounter [2].
In 2006, the US Food and Drug Administration (FDA) approved Gardasil, the first preventive HPV vaccine; the second, Cervarix was approved in 2009. Gardasil protects against HPV-6 and HPV-11 that cause about $80 \%$ of genital warts. This vaccine also protects against HPV-16 and HPV-18 that are believed to cause about $70 \%$ of cervical cancers 9 . It is given as a 3 -shot series over a six month time period (the need for booster shots is unknown at this time). Gardasil is currently approved women 9 through 26 years of age [10]. In October 2009 the FDA approved the use of Gardasil among men and boys. Cervarix was approved for use in girls and youg women ages 10-25 to help prevent cervical cancer in October 2009.

In 2007, the U.S. Army [11] Navy/Marine Corps [12] and Air Force [13] issued policies supporting the use of HPV vaccines as recommended by the CDC. Current Department of Defense policies for military women in each of the branches of service encourage HPV vaccination, but do not require it.

Womack Army Medical Center in Fort Bragg, North Carolina serves approximately 6,400 active duty females. All active duty soldiers receive full medical coverage, including vaccines. This study targeted active duty females in the FDA approved age range of 18 to 26 years for the Gardasil vaccine.

*Corresponding author: Cristóbal S. Berry-Cabán, Womack Army Medical Center, Department of Research, Fort Bragg, North Carolina, USA, Tel: 011-910907-8844; E-mail: cris.berrycaban@us.army.mil

Received February 07, 2011; Accepted March 16, 2011; Published March 19, 2011

Citation: LaRocque JD, Berry-Cabán CS (2011) Human Papilloma Virus Vaccination Coverage among Soldiers in a Military Treatment Facility, 2007-2010. $\mathrm{J}$ Vaccines Vaccin 2:116. doi:10.4172/2157-7560.1000116

Copyright: ( 2011 LaRocque JD, et al. This is an open-access article distributed under the terms of the Creative Commons Attribution License, which permits unrestricted use, distribution, and reproduction in any medium, provided the original author and source are credited. 
Citation: LaRocque JD, Berry-Cabán CS (2011) Human Papilloma Virus Vaccination Coverage among Soldiers in a Military Treatment Facility, 20072010. J Vaccines Vaccin 2:116. doi:10.4172/2157-7560.1000116

Page 2 of 3

\section{Methods}

Medical records of all female Soldiers aged 18 to 26 registered at Womack Army Medical Center $(\mathrm{n}=3,186)$ were examined retrospectively using the Composite Health Care System (CHCS) database. CHCS is a relational database used by all US military hospitals that provides automated medical information on uniformed service personnel, retirees and dependents.

Patients identified with a Current Procedural Terminology (CPT) 90649, Human Papillomavirus (HPV) vaccine code encounter were included. Data was collected for all patients between November 1, 2006 and December 15, 2009.

Data collected included only Gardasil; at the time of this study Gardasil was not available for use in boys and young men nor was Cervarix available.

Statistical analyses were conducted using SPSS version 17. Gardasil compliance data was analyzed using frequency distributions with calculations of means and confidence intervals of all responses.

This study was approved by the Womack Army Medical Center Institutional Review Board.

\section{Results}

A total 472 (14.8\%) female Soldiers aged 18 to 26, received at least one dose of the HPV vaccine Gardasil (Table 13 were 27 when they received the $2^{\text {nd }}$ or $3^{\text {rd }}$ injection). Of these, $174(36.79 \%)$ soldiers received 1 dose, $121(25.58 \%)$ received 2 doses and 177 (37.42\%) completed the 3 -dose vaccine series (Table 2 ).

Timing of the doses averaged 3.5 months between the first and

\begin{tabular}{|l|l|l|l|l|}
\hline Age & \multicolumn{2}{|l|}{ Total Soldiers $(\%, \mathbf{C l})$} & \multicolumn{2}{l|}{ Vaccinated Soldiers (\%, CI) } \\
\hline 18 & 46 & $1.4(1.0-1.9)$ & 14 & $3.0(1.4-4.5)$ \\
\hline 19 & 275 & $8.6(7.7-9.6)$ & 38 & $8.1(5.6-10.5)$ \\
\hline 20 & 318 & $9.9(8.9-11.0)$ & 58 & $12.3(9.3-15.2)$ \\
\hline 21 & 418 & $13.1(11.9-14.3)$ & 67 & $14.211 .0-17.3)$ \\
\hline 22 & 416 & $13.1(11.9-14.3)$ & 56 & $11.9(8.9-14.8)$ \\
\hline 23 & 444 & $13.9(12.7-15.1)$ & 67 & $14.2(11.0-17.3)$ \\
\hline 24 & 424 & $13.3(12.1-14.5)$ & 63 & $13.3(10.3-16.4)$ \\
\hline 25 & 437 & $13.7(12.5-14.9)$ & 74 & $15.7(12.4-19.0)$ \\
\hline$\geq 26^{*}$ & 408 & $12.8(11.6-14.0)$ & 36 & $7.6(5.2-10.0)$ \\
\hline Total & 3186 & & 472 & \\
\hline
\end{tabular}

*Includes females who were older than 26 when they received $2^{\text {nd }}$ or $3^{\text {rd }}$ injection Table 1: Prevalence of Vaccinated Female Soldiers, Womack Army Medical Center, 2007-2010.

\begin{tabular}{|l|l|l|l|l|l|l|l|}
\hline Age & \multicolumn{3}{|l|}{ 1 Dose (\%) } & \multicolumn{2}{l|}{ 2 Doses (\%) } & 3 Doses (\%) & \\
\hline 18 & 9 & $1.9(0.7-3.1)$ & 5 & $1.1(0.1-2.0)$ & 0 & \\
\hline 19 & 18 & $3.8(2.1-5.5)$ & 7 & $1.5(0.4-2.6)$ & 13 & $7.3(3.5-11.2)$ \\
\hline 20 & 18 & $3.8(2.1-5.5)$ & 17 & $3.6(1.9-5.3)$ & 22 & $12.4(7.6-17.3)$ \\
\hline 21 & 22 & $4.7(2.8-6.6)$ & 15 & $3.2(1.6-4.8)$ & 30 & $16.9(11.4-22.5)$ \\
\hline 22 & 23 & $4.9(2.9-6.8)$ & 8 & $1.7(0.5-2.9)$ & 25 & $14.1(9.0-19.3)$ \\
\hline 23 & 21 & $4.4(2.6-6.3)$ & 20 & $4.2(2.4-6.1)$ & 26 & $14.7(9.5-19.9)$ \\
\hline 24 & 24 & $5.1(3.1-7.1)$ & 17 & $3.6(1.9-5.3)$ & 22 & $12.4(7.6-17.3)$ \\
\hline 25 & 23 & $4.9(2.9-6.8)$ & 25 & $5.3(3.3-7.3)$ & 26 & $14.7(9.5-19.9)$ \\
\hline$\geq 26^{*}$ & 16 & $3.4(1.8-5.0)$ & 7 & $1.5(0.4-2.6)$ & 13 & $7.3(3.5-11.2)$ \\
\hline Total & 174 & & 121 & & 177 & \\
\hline
\end{tabular}

*Includes females who were older than 26 when they received $2^{\text {nd }}$ or $3^{\text {rd }}$ injection Table 2: Number of Doses for Vaccinated Female Soldiers, Womack Army Medical Center, 2007-2010.

\begin{tabular}{|l|l|l|}
\hline Age & $\begin{array}{l}\text { Time Interval between } \mathbf{1}^{\text {st }} \\
\text { and } \mathbf{2}^{\text {nd }} \text { dose (months) }\end{array}$ & $\begin{array}{l}\text { Time Interval between } \mathbf{2}^{\text {nd }} \text { and } \\
\mathbf{3}^{\text {rd }} \text { dose (months) }\end{array}$ \\
\hline 18 & 3.7 & 0 \\
\hline 19 & 3.4 & 3.7 \\
\hline 20 & 3.4 & 4.8 \\
\hline 21 & 4.0 & 4.7 \\
\hline 22 & 3.4 & 7.4 \\
\hline 23 & 3.7 & 4.8 \\
\hline 24 & 3.4 & 5.2 \\
\hline 25 & 3.3 & 7.8 \\
\hline$\geq 26^{*}$ & 3.3 & 4.4 \\
\hline $\begin{array}{l}\text { Average } \\
\text { (months) }\end{array}$ & 3.5 & 4.8 \\
\hline
\end{tabular}

*Includes females who were older than 26 when they received $2^{\text {nd }}$ or $3^{\text {rd }}$ injection Table 3: Timing of Doses.

second dose; the average time period between the second and third dose was 4.8 months (Table 3 ).

\section{Conclusions}

There are low rates of vaccine compliance among active duty females aged 18 to 26 at this MTF, however the rate is similar to the national average [14]. These are concerning results since thousands of women die each year from cervical cancer each year and are preventable with compliance with the HPV vaccine.

In addition to the relatively low compliance, this study shows that the recommended dosing intervals of 0,2 and 6 months set forth in the prescribing information are not stringently followed. Proper timing of injections is necessary for an adequate immune response and effectiveness of the vaccine. The combination of these two factors, low compliance and adherence to the vaccination protocol, suggests the need for intensified training to increase the protection of active duty females from cervical cancer.

At the time of this study Gardasil was not actively being marketed toward soldiers. However at the time of this study Merck did conduct a media blitz [15]. They are several ways, however, in which MTFs can initiate informational campaigns (posters, pamphlets, public service announcements) directed at active duty females in the 18 to 26 age range. Initial promotion would be most effective if staged within the hospital areas where females and their families receive the majority of their care. These areas include the family medicine, obstetrics and gynecology and pediatrics clinics. Further dissemination to clinics that support the MTF as well as units in which the target females serve would further ensure the message is reaching the intended audience.

To increase initiation of the vaccine series, steps should also be taken to educate providers in using required annual physicals to start a discussion of the vaccine and to administer the first dose. To increase the visibility of the vaccine, this education could be completed at educational lectures, at residency lectures or at staff meetings within clinic areas. These educational opportunities promote the physician buy-in that is required for successful completion of the series.

Further dissemination of information in the form of a "Vaccination Blitz" would help to increase compliance rates at all FDA approved ages. These campaigns have proven efficacy $[16,17]$.

Although this study focused on active duty females, current recommendations by the FDA and CDC encompass all females. The same promotion strategies utilized in key high traffic areas of an installation to target active duty females would also get the vaccination message to all patients who would benefit. 
Citation: LaRocque JD, Berry-Cabán CS (2011) Human Papilloma Virus Vaccination Coverage among Soldiers in a Military Treatment Facility, 20072010. J Vaccines Vaccin 2:116. doi:10.4172/2157-7560.1000116

Page 3 of 3

This study has several limitations. Because of the transient nature of soldiers and military families, interruption of the injection series due to moves or deployments may have occurred. Military families, on average, spend 3 years garrison before relocating to another installation. This break in access while re-locating can cause the omission of required injections in the series.

While all MTFs utilize the same electronic medical record, data transfer between installations is not complete in regard to vaccinations. Additionally, updated records of soldier's immunizations are compiled through a central database that requires providers to manually input these data into the patient's medical record. When soldiers are deployed during wartime, the vaccinations available in-country is not guaranteed to be available in field hospitals down-range.

Our study is intended to remind providers to utilize the annual physical as an opportunity to initiate the HPV vaccine series and the importance of completing the entire series in all eligible females.

\section{Acknowledgments}

Ms. Charlene C Colon, Clinical Data Services, Information Management Division, WAMC conducted the data extraction from $\mathrm{CHCS}$.

\section{References}

1. Throop MD (2010) After the Vaccine: Cervical Cancer Screening in Army Women. Washington, DC: School of Nursing, The Catholic University of America.

2. Armed Forces Health Surveillance Center (2010) Sexually Transmitted Infections, U.S. Armed Forces, 2004-2009. Medical Surveilance Monthly Report 17: 2-10.

3. Niebuhr DW, Tobler SK, Jordan NN, DE. S. Sexually Transmitted Infections Among Military Recruits. In: BL D, ed. Recruit Medicine. Falls Church, VA: United States Army, Office of the Surgeon General; 2006: 255-275.

4. Centers for Disease Control and Prevention (2008) Vaccination Coverage Among Adolescents Aged 13--17 Years --- United States, 2007 MMWR 57:1100-1103.
5. Von Sadovszky V, Ryan Wenger N (2007) Army women's sexual health information needs. J Obstet Gynecol Neonatal Nurs 36: 348-357.

6. Yamane G (2006) Cancer incidence in the US Air Force: 1989-2002. Aviat Space Environ Med 77:789-794.

7. Bosch FX, de Sanjose S (2003) Chapter 1: Human papillomavirus and cervica cancer-burden and assessment of causality. J Natl Cancer Inst Monogr 2003 3-13.

8. Centers for Disease Control and Prevention (2006) Sexually Transmitted Diseases Treatment Guidelines, 2006. MMWR Recomm Rep 55: 1-94.

9. American Cancer Society. Detailed Guide: Cervical Cancer; What Are the Key Statistics About Cervical Cancer? 2008; http://www.cancer.org/docroot/CRI/ content/CRI_2_4_1X_What_are_the_key_statistics_for_cervical_cancer_8. asp. Accessed March 23, 2009

10. Merck \& Co (2008) Highlights of Prescribing Information: Gardasil. 9883609 Accessed March 24, 2009.

11. US Army Medical Command. Provisional Recommendations on Use of Quadrivalent Human Papillomavirus (HPV) Vaccine. 2007; http://www. vaccines.mil/documents/1046HPVmemo.pdf. Accessed March 9, 2007.

12. Bureau of Medicine and Surgery. Recommendations for the Use of Quadrivalent Human Papilloma Virus (HPV) Vaccine in Navy and Marine Beneficiaries. 2007; http://www.vaccines.mil/documents/1067NAVMED_Policy_07_017.pdf. Accessed May 17, 2007.

13. US Department of the Air Force. Human Papillomavirus Vaccination Policy 2007; http://www.vaccines.mil/documents/1062AFHumanPapillomavirusPolicy Apr2007.pdf. Accessed April 13, 2007.

14. Jain N, Euler G, Shefer A, Lu P, Yankey D, Markowitz L, et al. (2009) Human papillomavirus (HPV) awareness and vaccination initiation among women in the United States, National Immunization Survey-Adult 2007. Prev Med 48: 426-431.

15. Rothman SM, Rothman DJ (2009) Marketing HPV vaccine: implications for adolescent health and medical professionalism. JAMA 302: 781.

16. Kunze M, Kunze U (2003) Social marketing and the establishment of the ISWTBE. Vaccine 21: S62-S65.

17. Basch PF (1994) Vaccines and world health: science, policy, and practice. New York: Oxford University Press. 